\title{
Assessment of surgeon experience with femtosecond laser-assisted cataract surgery
}

This article was published in the following Dove Press journal:

Clinical Ophthalmology

\author{
Christian Song ${ }^{1,2}$ \\ Connor J Baharozian ${ }^{3}$ \\ Kathryn M Hatch ${ }^{1,2}$ \\ Jonathan H Talamo ${ }^{1,2}$ \\ 'Department of Opthalmology, \\ Massachusetts Eye and Ear Infirmary, \\ Boston, MA, USA; ${ }^{2}$ Department \\ of Ophthalmology, Harvard \\ Medical School, Boston, MA, USA; \\ ${ }^{3}$ Department of Opthalmology, Boston \\ University School of Medicine, Boston, \\ MA, USA
}

Purpose: To evaluate the collective user experience with an image-guided femtosecond laser (FSL) for cataract surgery in a high-volume, multi-surgeon, ambulatory surgical center.

Subjects and methods: A detailed online survey was distributed to all surgeons in a single ambulatory surgical center who had performed cataract surgery using a FSL since its acquisition in December 2012. Information collected included the number of cases performed, typical surgical techniques and parameters, satisfaction with individual features of the laser (rated on a scale from $1=$ completely unsatisfied to $10=$ extremely satisfied) and commentary on ease of use and suggested improvements.

Results: Seventeen of 30 surgeons (56.7\%) completed the survey, representing a case volume of 1,967 eyes. Fourteen surgeons $(82.4 \%)$ felt they required $\leq 10$ cases with the FSL to operate with the same safety and control as in standard phacoemulsification surgery. Satisfaction was highest for capsulotomies, lens fragmentation, lens softening, arcuate incisions and the graphic user interface (mean scores 9.4, 8.7, 8.7, 7.2 and 8.9, respectively). Preferred capsulotomy diameter was $4.8-5.2 \mathrm{~mm}$ ( $64.7 \%$ of respondents). About half $(52.9 \%)$ of respondents centered the capsulotomy on the pupil and the other $47.1 \%$ centered the capsulotomy using optical coherence tomography. Most respondents (81.3\%) preferred transepithelial arcuate incisions compared to intrastromal incisions. Satisfaction was lowest with FSL-created, main, clear corneal incisions and paracenteses (mean scores 4.4 and 4.2, respectively).

Conclusion: Laser-assisted cataract surgery has a short learning curve and a high rate of user satisfaction. Further software and hardware development is warranted to improve user satisfaction with peripheral and clear corneal incisions.

Keywords: survey, satisfaction, learning curve, performance, Catalys, FLACS, capsulorhexis

\section{Introduction}

Femtosecond laser-assisted cataract surgery (FLACS) represents one of the largest shifts in the evolution of cataract surgery technology since the introduction of phacoemulsification 50 years ago. Some of its advantages over standard phacoemulsification include reduced phacoemulsification time and lower endothelial cell loss, as well as improved visual recovery and refractive stability. ${ }^{1-3}$ These advantages must offset the added cost, potential disruption in surgical flow and training necessary for FLACS to be widely adopted., ${ }^{4,5}$ Advocates of the technology maintain that once surgeons overcome the learning curve, the benefits of FLACS meet or exceed those of standard phacoemulsification in clinical outcomes and safety ${ }^{6.7}$ While several studies have evaluated surgical outcomes and complications associated with FLACS, little information exists on direct surgeon assessment of this new technology, including the "learning curve". To assess surgeons' real-world experience with FLACS, we sought direct feedback by distributing a detailed survey to all surgeons who had performed FLACS
Correspondence: Christian Song

Massachusetts Eye and Ear Infirmary 243 Charles Street, Boston, MA 02II4, USA Email christian_song@meei.harvard.edu (c)
hereby accept the Terms. Non-commercial uses of the work are permitted without any further permission from Dove Medical Press Limited, provided the work is properly attributed. For permission for commercial use of this work, please see paragraphs 4.2 and 5 of our Terms (https://www.dovepress.com/terms.php).
her 
at a single, high-volume, ambulatory surgical center (ASC). The survey was designed to help identify common surgical techniques and parameters, satisfaction with the femtosecond laser (FSL) and surgeons' opinion on ease of use.

\section{Subjects and methods}

This study was approved by a national Institutional Review Board (Quorum, Olympia, WA, USA), and it followed the tenets of the Declaration of Helsinki. A detailed questionnaire was distributed to all surgeons in a single ASC (Waltham, MA, USA) who had performed FLACS using the Catalys laser platform (Johnson \& Johnson Vision, Inc, Santa Ana, CA, USA) between December 2012, when the apparatus was first acquired, and October 2015. The survey was made available via an online link and in paper format. Participation was voluntary and a statement was provided affirming that all surgeon identifiers and collected data would be kept strictly confidential.

The survey queried surgeons for their estimated number of cases performed and FLACS experience encompassing each step of the surgery from docking to the final corneal incisions. An inquiry on surgical technique and parameters included typical capsulotomy sizes, lens fragmentation and softening patterns, and usage of peripheral corneal and arcuate incisions. Questions addressing ease of use included estimated percentages of docking attempts, suction loss and the number of cases needed to attain the same level of comfort and safety as with standard phacoemulsification. Respondents were also asked to provide satisfaction ratings (rated on a scale from $1=$ completely unsatisfied to $10=$ extremely satisfied) on docking, capsulotomy, lens fragmentation, lens softening, arcuate incisions, peripheral corneal incisions, clear corneal incisions (CCI) and the graphic user interface. Surgeon identifiers were used only to determine the total number of cases performed during the study period and were kept strictly confidential. One of the study authors (JHT) was formerly Medical Director of the ASC until September 14, 2014 and remained on the Board of Directors until August 2016. However, all surgeonspecific information obtained in this study was masked to all authors except CS.

\section{Results}

The survey was completed by 17 of 30 surgeons $(56.7 \%)$ representing a volume of 1,967 out of 2,494 total cases (78.9\%). This represented a wide spectrum of experiences, with the number of cases performed by each surgeon ranging from 5 to 379 (mean 115.7 \pm 127.4 ).

\section{Technique}

The majority of respondents $(64.7 \%)$ reported preferring a capsulotomy diameter of 4.8-5.2 mm. Five surgeons (29.4\%) routinely selected a capsulotomy diameter of 5.3-5.5 mm, while only one preferred using a diameter $>5.5 \mathrm{~mm}$. The method by which the capsulotomy was centered was divided nearly evenly between pupil-centered (52.9\%) and optical coherence tomography-scanned capsule (47.1\%) centration. Only 2 of 17 surgeons reported creating peripheral corneal incisions and CCI for the main wound with the laser. All surgeons reported using the laser to aid in fragmentation and softening of the lens, with the majority (76.5\%) using a four-piece fragmentation pattern and the remaining surgeons using either six-piece or variable fragmentation patterns.

All respondents except one reported using arcuate incisions for the management of astigmatism. Of these, 13 of $16(81.3 \%)$ preferred transepithelial incisions only, 2 of $16(12.5 \%)$ preferred intrastromal incisions only and one surgeon regularly used both. In contrast, only 2 of 17 (11.8\%) surgeons reported routinely using the laser to create peripheral corneal incisions and CCI. Common reasons given were "manual are faster" and "manual are more accurate". Some surgeons also expressed concern that the FLACS incisions were too central.

\section{Satisfaction}

Surgeon satisfaction scores for various aspects of the FSL are shown in Figure 1. The capsulotomy, graphic user interface, lens softening and lens fragmentation functions were rated the highest. Surgeons were least satisfied with the laser's ability to produce peripheral corneal incisions and CCI.

\section{Ease of use}

The majority of respondents $(82.3 \%)$ reported requiring $\leq 10$ cases of FLACS to feel confident they could perform cataract surgery with the same level of safety as with standard phacoemulsification. Nearly all surgeons (94.1\%) reported needing multiple docking attempts on at least one case, with 12 surgeons $(70.6 \%)$ estimating that $<5 \%$ of their cases required multiple attempts. One surgeon estimated requiring multiple docking attempts on about $20 \%$ of cases, while another estimated this was an issue in about $50 \%$ of cases. Suction loss was also a problem encountered by nearly all surgeons $(88.2 \%)$ at least once. Four surgeons $(23.5 \%)$ reported at least one instance of an incomplete capsulotomy.

\section{Discussion}

This study sought to identify the positive aspects and potential limitations of FLACS from the practical view of 


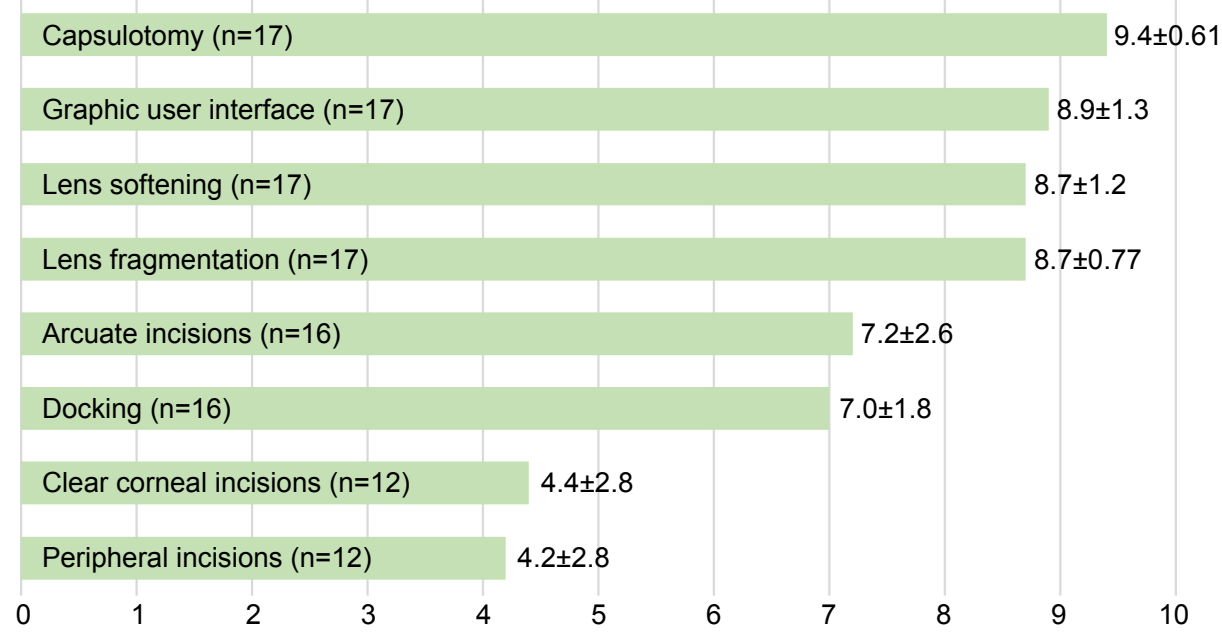

Figure I Surgeon satisfaction ratings for individual features of the femtosecond laser (mean $\pm S D$ ).

cataract surgeons. Achieving FLACS competence requires customization of a variety of parameters to achieve a safe, efficient and successful cataract surgery. Several investigators have reported an increase in complication rates during early experience with the FSL. ${ }^{6,7}$ While it was not possible to determine precisely complication rates from our survey, most surgeons reported requiring $\leq 10$ cases to feel they could perform FLACS with the same level of safety as with standard phacoemulsification. Thus, comfort using the FSL appears readily achievable with a short learning curve from a subjective standpoint. This appears to be corroborated by a separate analysis we performed of all surgeons at this ASC in which the vitreous loss rates were similar between standard phacoemulsification cataract surgery and FLACS. It was also no higher in early FLACS cases compared to late FLACS cases. ${ }^{8}$

A manual circular curvilinear capsulorhexis that is well centered and of appropriate diameter is often considered the most challenging, yet most important step in cataract surgery. ${ }^{9,10}$ Capsulotomies created with the FSL result in less intraocular lens (IOL) decentration and tilt compared to manual capsulorhexis, correlating with improved bestcorrected distance visual acuity and refractive stability, and may also improve IOL power calculation predictability. ${ }^{11-13}$ Surgeons traditionally center the capsulorhexis with respect to the dilated pupil with standard phacoemulsification surgery and, by extension, will often do so with FLACS. Optical coherence tomography-guided scanned capsule centration of the capsulotomy is a unique feature of the Catalys system that enables centration of the capsulotomy relative to the lens equator. Almost half (47\%) of surgeons in this survey preferred this method of capsulotomy positioning. While this may not align universally with the optical axis of the eye, the presumption is that IOLs have a natural tendency to migrate toward the center of the capsular bag due to the centrifugal forces exerted by the haptics against the capsular equator. ${ }^{14}$ Additionally, most surgeons preferred a capsulotomy diameter of 4.8-5.2 mm, which would ensure an adequate $360^{\circ}$ overlap of a $6.0 \mathrm{~mm}$ diameter optic characteristic of the single-piece open-loop IOLs most commonly used at the surgical center. Being able to automate the creation of a highly precise, reproducible capsulotomy within seconds with the FSL received the highest satisfaction rating, which attests to the importance of this step. However, it should be noted that several surgeons reported instances of an incomplete capsulotomy. It is, therefore, essential to always ensure that no tags remain prior to removing the capsulotomy, so as to avoid causing an aberrant capsular tear.

Achieving the desired depth, length and angulation of arcuate incisions is more precise and consistent with the FSL compared to manual incisions. ${ }^{15,16}$ FSL-enabled arcuate incisions received good satisfaction ratings in this survey, though with greater variability. We surmise that a lack of established nomograms in the literature as of the time this survey was conducted may have resulted in less predictable outcomes and, therefore, reduced satisfaction for some surgeons. Recently published nomograms for both transepithelial and intrastromal arcuate incisions provide a useful starting point. ${ }^{17-19}$ However, additional data and refinement of nomograms will improve predictability and outcomes.

Only two surgeons reported regularly using the laser to create peripheral corneal incisions. The laser adds several seconds to the total treatment time to create the incision which is then opened in the operating room. Most surgeons 
are comfortable fashioning their corneal incisions efficiently with a keratome blade in a single pass. The opinion that laser incisions are less accurate reflects the possibility of the incisions being placed more anteriorly than desired to ensure the posterior-most laser pulses are not impeded by the sclera or limbus, or inadvertently placed on an axis that may be less ergonomic to the surgeon or incorrect when surgically induced astigmatism is being factored.

Despite these criticisms, there is some evidence in the literature supporting FSL-created incisions. Reduced endothelial and epithelial gaping, endothelial misalignment, Descemet's membrane detachment and posterior wound retraction with FSL-created CCI compared to manual CCI have been reported. ${ }^{20,21}$ There appear to be no differences in wavefront aberrations between manual and FSL incisions. Mastropasqua et $\mathrm{al}^{21}$ reported there was no significant increase in corneal higher order aberrations in either FSL or manual CCI. Nagy et $\mathrm{al}^{22}$ found a significant increase in corneal higher order aberrations in both FSL and manual CCI postoperatively, but no significant difference in the root mean square values between the two groups. Additionally, they reported that the magnitude of surgically induced astigmatism was similar between the two groups. There was significantly less deviation from the intended axis with the FSL group compared to the manual group. This may help improve predictability of refractive outcomes in cataract surgery cases involving concurrent astigmatic treatment.

With a response rate of $53.1 \%$ to the survey request, the potential for voluntary response and nonresponse bias is a limitation of the survey results. This sample of submissions may overrepresent individuals who share similar techniques or opinions. However, the broad range of case volumes represented among the respondents (ranging from 5 to 379) suggests some success in capturing the perspectives of surgeons of diverse levels of experience and skill. Additionally, those who submitted a response may have rated their experience more positively than they would normally, to avoid potential repercussions, despite a statement of confidentiality and assurance against any consequences given at the beginning of the survey. It is also possible that many surgeons have either discontinued or have not yet pursued FLACS perhaps due to a negative perception of the technology, such as financial constraints and reduced operative efficiency. Efforts to broaden the scope of the survey to include these surgeons may help to offset some of the aforementioned biases. Another limitation of this report is that the surgeons performed FLACS only on the Catalys laser system. There are many variations in the design, patient interface, method of docking, user interface and treatment parameters across the available laser platforms, any of which may affect a surgeon's experience and opinions on FLACS.

This survey demonstrated a general consensus among FLACS surgeons on features of the FSL that functioned well and those that were less satisfactory. Surgeons were comfortable using the laser within their first few cases and highly rated the user interface, suggesting relative ease navigating and adjusting settings. Capsulotomies, lens fragmentation and softening, and arcuate incisions were also well rated and used regularly. Dissatisfaction was greatest with peripheral corneal incisions and CCI. Further development to improve the accuracy and reliability of peripheral corneal incisions and CCI is warranted.

\section{Acknowledgments}

The results of this study were presented at the American Society of Cataract and Refractive Surgery Annual Symposium and Congress, New Orleans, LA, May 6-10, 2016. Funded by an unrestricted grant from Johnson \& Johnson Vision, Inc., Santa Ana, CA, USA.

\section{Disclosure}

Mr Baharozian and Dr Song have no proprietary or commercial interest in any material discussed in this article. Dr Hatch is a consultant for Johnson \& Johnson Vision, Inc. Dr Talamo was a consultant to Johnson \& Johnson Vision, Inc. and is now an employee. The other authors report no conflicts of interest in this work.

\section{References}

1. Abell RG, Kerr NM, Vote BJ. Toward zero effective phacoemulsification time using femtosecond laser pretreatment. Ophthalmology. 2013; 120(5):942-948.

2. Conrad-Hengerer I, Al Sheikh M, Hengerer FH, Schultz T, Dick HB. Comparison of visual recovery and refractive stability between femtosecond laser-assisted cataract surgery and standard phacoemulsification: six-month follow-up. J Cataract Refract Surg. 2015;41(7): 1356-1364.

3. Conrad-Hengerer I, Al Juburi M, Schultz T, Hengerer FH, Dick HB. Corneal endothelial cell loss and corneal thickness in conventional compared with femtosecond laser-assisted cataract surgery: three-month follow-up. J Cataract Refract Surg. 2013;39(9):1307-1313.

4. Feldman BH. Femtosecond laser will not be a standard method for cataract extraction ten years from now. Surv Ophthalmol. 2015;60(4): 360-365.

5. Ranka M, Donnenfeld ED. Femtosecond laser will be the standard method for cataract extraction ten years from now. Surv Ophthalmol. 2015;60(4):356-360.

6. Roberts TV, Lawless M, Bali SJ, Hodge C, Sutton G. Surgical outcomes and safety of femtosecond laser cataract surgery: a prospective study of 1500 consecutive cases. Ophthalmology. 2013;120(2):227-233.

7. Nagy ZZ, Takacs AI, Filkorn T, et al. Complications of femtosecond laserassisted cataract surgery. J Cataract Refract Surg. 2014;40(1):20-28. 
8. Song C, Baharozian CJ, Hatch KM, Grassett GC, Talamo JH. Rate of unplanned vitrectomies in femtosecond, laser-assisted, cataract surgery compared to conventional phacoemulsification in a multi-surgeon, ambulatory, surgical center. J Refract Surg. In press 2018.

9. Mccannel CA, Reed DC, Goldman DR. Ophthalmic surgery simulator training improves resident performance of capsulorhexis in the operating room. Ophthalmology. 2013;120(12):2456-2461.

10. Dooley IJ, O'Brien PD. Subjective difficulty of each stage of phacoemulsification cataract surgery performed by basic surgical trainees. J Cataract Refract Surg. 2006;32(4):604-608.

11. Kránitz K, Miháltz K, Sándor GL, et al. Intraocular lens tilt and decentration measured by Scheimpflug camera following manual or femtosecond laser-created continuous circular capsulotomy. J Refract Surg. 2012;28(4):259-263.

12. Filkorn T, Kovács I, Takács A, et al. Comparison of IOL power calculation and refractive outcome after laser refractive cataract surgery with a femtosecond laser versus conventional phacoemulsification. $J$ Refract Surg. 2012;28(8):540-544.

13. Kránitz K, Takacs A, Miháltz K, et al. Femtosecond laser capsulotomy and manual continuous curvilinear capsulorrhexis parameters and their effects on intraocular lens centration. J Refract Surg. 2011;27(8): 558-563.

14. Findl O. Intraocular lens materials and design. Colvard M, editor. Achieving Excellence in Cataract Surgery: A Step-by-Step Approach. Available from: https://cybersight.org/wp-content/uploads/ 2018/01/Achieving-Excellence-in-Cataract-Surgery.pdf. Accessed April 20, 2018
15. Soong HK, Malta JB. Femtosecond lasers in ophthalmology. Am J Ophthalmol. 2009;147(2):189-197.

16. Gray B, Binder PS, Huang LC, Hill J, Salvador-Silva M, Gwon A. Penetrating and Intrastromal Corneal Arcuate Incisions in Rabbit and Human Cadaver Eyes: Manual Diamond Blade and Femtosecond Laser-Created Incisions. Eye Contact Lens. 2016;42(4):267-273.

17. Chan TC, Cheng GP, Wang Z, Tham CC, Woo VC, Jhanji V. Vector analysis of corneal astigmatism after combined femtosecond-assisted phacoemulsification and arcuate keratotomy. Am J Ophthalmol. 2015; 160(2):250-255.

18. Day AC, Lau NM, Stevens JD. Nonpenetrating femtosecond laser intrastromal astigmatic keratotomy in eyes having cataract surgery. $J$ Cataract Refract Surg. 2016;42(1):102-109.

19. Baharozian CJ, Song C, Hatch KM, Talamo JH. A novel nomogram for the treatment of astigmatism with femtosecond-laser arcuate incisions at the time of cataract surgery. Clin Ophthalmol. 2017;11: 1841-1848.

20. Grewal DS, Basti S. Comparison of morphologic features of clear corneal incisions created with a femtosecond laser or a keratome. $J$ Cataract Refract Surg. 2014;40(4):521-530.

21. Mastropasqua L, Toto L, Mastropasqua A, et al. Femtosecond laser versus manual clear corneal incision in cataract surgery. J Refract Surg 2014;30(1):27-33.

22. Nagy ZZ, Dunai A, Kránitz K, et al. Evaluation of femtosecond laserassisted and manual clear corneal incisions and their effect on surgically induced astigmatism and higher-order aberrations. J Refract Surg. 2014;30(8):522-525.
Clinical Ophthalmology

\section{Publish your work in this journal}

Clinical Ophthalmology is an international, peer-reviewed journa covering all subspecialties within ophthalmology. Key topics include: Optometry; Visual science; Pharmacology and drug therapy in eye diseases; Basic Sciences; Primary and Secondary eye care; Patient Safety and Quality of Care Improvements. This journal is indexed on

Submit your manuscript here: http://www.dovepress.com/clinical-ophthalmology-journal

\section{Dovepress}

PubMed Central and CAS, and is the official journal of The Society of Clinical Ophthalmology (SCO). The manuscript management system is completely online and includes a very quick and fair peer-review system, which is all easy to use. Visit http://www.dovepress.com/ testimonials.php to read real quotes from published authors. 